\title{
Article \\ Rethinking a Designers' Rule of Thumb: Influence of Information Seeking and Consumption Goals on Mobile Commerce Interface Design
}

\author{
Sooa Hwang ${ }^{1}$, Hyunah Park ${ }^{2}$, Kyunghui Oh ${ }^{3}$, Sangwoong Hwang ${ }^{3}$ and Jaewoo Joo ${ }^{2, *}$ (D) \\ 1 Marketing Department, Sogang University, Seoul 04107, Korea; sooahwang@sogang.ac.kr \\ 2 Marketing Department, College of Business Administration, Kookmin University, Seoul 02707, Korea; \\ hyunah_park@kookmin.ac.kr \\ 3 Design Corporate Center, Samsung Electronics, Seoul 06765, Korea; kh158.oh@samsung.com (K.O.); \\ s.w.hwang@samsung.com (S.H.) \\ * Correspondence: designmarketinglab@gmail.com; Tel.: +82-2-910-5523; Fax: +82-2-910-5209
}

check for updates

Citation: Hwang, S.; Park, H.; Oh, K.; Hwang, S.; Joo, J. Rethinking a

Designers' Rule of Thumb: Influence of Information Seeking and Consumption Goals on Mobile Commerce Interface Design.

J. Theor. Appl. Electron. Commer. Res. 2021, 16, 1631-1647.

https://doi.org/10.3390/

jtaer16050092

\section{Academic Editors:}

Dan-Cristian Dabija, Cristinel Vasiliu and Rebeka-Anna Pop

Received: 3 April 2021

Accepted: 14 May 2021

Published: 19 May 2021

Publisher's Note: MDPI stays neutral with regard to jurisdictional claims in published maps and institutional affiliations.

Copyright: (C) 2021 by the authors Licensee MDPI, Basel, Switzerland. This article is an open access article distributed under the terms and conditions of the Creative Commons Attribution (CC BY) license (https:/ / creativecommons.org/licenses/by/ $4.0 /)$.

\begin{abstract}
We investigated whether adding product information in mobile commerce improved consumers' attitudes toward a product and whether this relationship was moderated by consumption goals. We conducted two field experiments in which we recruited parents in Korea and the USA and asked them how they evaluated two childcare hybrid products (HPs) newly developed by Samsung Electronics designers. The results revealed that participants exposed to additional information about the HPs evaluated them more favorably than those who were not exposed. However, this relationship disappeared when a consumption goal was activated. Our findings establish a dynamic relationship between information seeking and consumption goals, asking designers to rethink their rule of thumb in the mobile commerce context.
\end{abstract}

Keywords: information seeking; consumption goal; hybrid product; Samsung Electronics; mobile commerce

\section{Introduction}

With the rapid advancement of mobile technology and the ICT environment, the smartphone has become the primary platform for e-commerce [1]. According to the 2018 Global M-Commerce report published by [2], 54\% of global e-commerce sales are expected to be made through smartphones by 2021. A large volume of research on mobile commerce has covered the topic in a wide range of areas. Ngai and Gunasekaran [3] classified literature on mobile commerce into five categories, including applications and cases, wireless user infrastructure, mobile middleware, wireless network infrastructure, and consumer behavior. In more recent literature, Ahmad and Ibrahim [4] suggested interface design guidelines to enhance the user experience in mobile commerce. Although mobile commerce has a lot in common with online commerce, consumers behave differently when they shop on their smartphones than when they do on their computers because their behaviors are influenced by screen size. They use a significantly smaller-sized screen when shopping in a mobile context compared to when they shop in an online context [5]. As such, researchers often suggest that mobile commerce designers ease consumers' cognitive burdens and improve their shopping experiences [6] because smartphones convey limited information with simple visual displays due to their small-sized screens [7]. They are encouraged, for example, to design mobile pages simply so that users are not distracted, but navigate them intuitively [8]. Similarly, designers are discouraged to add steps that consumers perform before reaching the final page. Indeed, recently popular mobile pages either replace click buttons with swipe buttons or even hide information.

However, we raise an important issue that UI designers ignore. That is, they pay attention to the usability of a mobile application [9] while overlooking its critical role: 
providing information and facilitating transactions [10]. More specifically, designers' practice of decreasing consumers' activities in order to improve usability suffers from two issues: First, decreasing activities does not guarantee higher usability. For instance, some studies have found no correlation between the number of clicks and navigation ease [11]. Others have found that the number of clicks is not crucial for an optimal experience. Instead, clarity of the content of each click matters [12]. These studies suggest that more than click numbers or page numbers should be considered to maximize usability. Second, more importantly, higher usability does not guarantee commercial success. Recent academic discussions about mobile commerce have limited their attention to usability, including ease of use, emotional valence, and perceived system value. Improving usability generally enhances users' mood and their satisfaction, but there is no evidence that doing so increases consumers' purchase-related behaviors [13]. In sum, contemporary UI designers' focus on ease of use may not always lead to commercially successful mobile applications.

In the present work, we shed light on the missing puzzle piece of mobile commerce by highlighting its commercial impact, which is ignored in prior academic discussions. More specifically, we focus on how UI in the mobile context changes consumers' product attitudes, which are one of the commercial aspects of UI. We hypothesize that, in contrast to the misperception designers have, adding information about a product improves consumers' attitudes toward the product. Our hypothesis is in line with the recent findings that consumers increase purchase intention and avoid risky decision-making when receiving more information, suggesting that addressing information-seeking behavior benefits consumers $[14,15]$. Drawing from the literature that consumers seek information to reduce uncertainty [16], we propose that adding information can increase consumers' product attitudes when the product entails uncertainty. We go one step further to propose that consumers' attitudes toward a product can even increase by not adding information, but activating a consumption goal [17]. We argue that a consumption goal plays a significant role when UI designers seek to showcase products in the mobile context.

While we investigate consumers' attitudes about a product, we pay particular attention to hybrid products (HPs). HPs consist of more than two normally disjointed and often categorically dissimilar products [18]. As HPs have been spotlighted by globally leading manufacturers such as Samsung Electronics, marketers and designers are struggling to take adequate actions to increase their sales. Interestingly, however, relatively little attention has been given to HPs as compared to other new products such as really new products (RNPs), which consist of new technologies, require consumer learning, and induce behavior changes (e.g., Sony's game machine, P\&G's clothing system, or LG's Styler $[19,20])$. Previously identified strategies for improving consumer attitudes about RNPs do not apply to HPs because HPs differ from RNPs in that HPs do not include new-to-market technology [21].

We call for attention to the fact that we address a unique issue related to HPs compared to prior HP research. Previous work has highlighted which product should be added to an existing one to develop attractive HPs. Therefore, similarity or structural alignment between multiple products has been the research focus [18]. In the present work, we study how to improve consumers' attitudes toward HPs by assuming that the HPs have already been developed. Therefore, our research question is more aligned to studies about psychological approaches to new product adoption [22].

The remaining sections of this research progress as follows: We review the literature on HPs, information seeking, and goals. We then develop a framework in which consumers' attitudes toward HPs in the mobile shopping environment improve when additional information is provided and a consumption goal is activated. We hypothesize that when consumers have not activated a goal, additional information about products would improve their attitudes toward HPs. In contrast, consumers with an activated goal have a high level of product attitude even before additional information is provided; therefore, the effect shown in the without-goal condition is weakened. Two main experiments were conducted to test our hypotheses by manipulating the amount of information and goal activation. 
We conclude with a discussion of the implications of key findings and suggestions for future research.

\section{Literature Review}

\subsection{The Benefits of Uncertainty About Hybrid Products (HPS)}

New product adoption is actively discussed among marketing researchers because new products fail at a stunning rate of between $40 \%$ and $90 \%$, and the odds have not changed much in the past 25 years [23]. A total of $47 \%$ of first movers have failed, meaning that approximately half the companies that pioneered new product categories later pulled out of business. Researchers agree that uncertainty about a new product is why consumers hesitate to purchase it; this has consequences for the failure of product adoption in the market. Studies investigating the type of uncertainties carried by new products state that there is "a substantial uncertainty when consumers try to predict a product's future utility", particularly concerning "the degree of uncertainty in regard to financial, functional, and social consequences of using a new product" [24-26].

Therefore, numerous marketing studies have explored how to reduce uncertainty about new products. One of the well-known strategies is developing HPs by combining more than "two normally disjoint products", which often involve products from dissimilar categories [18]. Examples include an HP made up of a toaster and a radio (De Longhi's Kenwood Radio Toaster with built-in FM Radio) and an HP composed of a mobile phone and a glucose level monitor (the KP 8400 from LG Electronics, Seoul, Korea). Prior studies on HPs have tended to focus on which products to select and then combine [18,27].

Regardless of which products are selected and combined to form a HP, it is still difficult for consumers to make sense of the HP's benefits. Therefore, the manufacturer's biggest challenge comes from the uncertainty caused by the conflicts between seemingly unrelated products [18]. Even when similar products are combined to form a HP, consumers often find it difficult to understand, limiting its adoption in the marketplace [27].

One way to resolve the benefit uncertainty of HPs is to provide information about their product category. Psychologists claim that people do not spontaneously form a category for multiple concepts. When prompted, however, they reflect about a salient goal or appropriate usage situation wherein two concepts interrelate meaningfully [28,29]. One group of researchers borrowed this concept and demonstrated that category labels helped consumers establish the relationship between two products and understand an $\mathrm{HP}^{\prime}$ s benefit [18]. People fail to connect the multiple products of a HP and therefore are unable to clearly understand its benefit unless a common denominator is identified.

In the present work, we propose different ways to reduce the benefit uncertainty consumers may associate with HPs. More specifically, we consider two variables that UI designers can easily manage in the mobile commerce context. They are (1) information seeking and (2) consumption goals.

\subsection{Information Seeking}

Uncertainty "triggers" or increases the amount of information-seeking behavior [30,31]. This behavior is defined as the motivating activation of knowledge stored in memory or information acquisition from the environment [32]. The literature on information seeking is voluminous and possesses a long and rich history. Virtually all consumer behavior textbooks contain extensive discussions of information seeking [33], and multiple review papers have been published in different decades $[34,35]$. According to research, consumers engage in informationseeking behavior to collect desirable product information [36]. Since this behavior is dominated by a utilitarian motivation, purchasing a product within a mental due date [17] aims to reduce uncertainty about buying it [37]. Indeed, multiple works and their subsequent studies suggest information seeking is a means of reducing uncertainty [38,39]. For example, information about the price and the brand name is particularly known to lower product uncertainty.

When consumers confront uncertain product purchase situations, they make a decision based on perceived product benefits [40]. Since they are influenced by numerous types 
and formats of product information [41], information-seeking behavior unquestionably increases purchase intentions or "what we think we will buy" [42]. This holds regardless of whether seeking information internally through the recall of a prior shopping experience or externally through a website or mobile page because it is based on the consumer's state of knowledge. While confidence in the decision-making process affects consumers' choices, information-seeking processes reduces uncertainty and increases confidence [43]. The way a mobile commerce interface is designed for information access may also influence consumers' knowledge-forming processes and actions. [44] noted that consumers now become so-called "information players", because the consumers are more actively engaged with information search activities and at the same time, they are easily distracted by alternative choices. Although the revenue impact of an introduction page is generally positive as it draws more customers to a store, the effect is limited by consumer segments and product types [42].

Information-seeking behavior plays a critical role, particularly when a product induces benefit uncertainty (e.g., HPs). Consumers find it challenging to understand the benefits of a product when it does not belong to any single existing category [45]. Therefore, a greater understanding of a product's benefit leads to favorable evaluations and increased adoption intentions [46]. This is consistent with an insightful finding of new product adoption that among the five aspects of a new product which determine its adoption rate, the relative benefit of a new product compared to an existing product is particularly influential [47]. This occurs frequently because a new product does not belong to any preexisting category, and consumers find it difficult to reflect their established memories [48]. In such cases, information-seeking behavior helps consumers lower uncertainty about a product's benefit [49]. Research suggests that the type of information also has a critical role. For example, when information about a product is a visual image, consumers decode the message by using it [50] or show a higher purchase intention because they get more involved in the product by enlarging it $[51,52]$. A study shows that consumers find product descriptions useful in enhancing product knowledge by comparing it with the product image [53]. This suggests that when a product is unfamiliar and the information about it is presented in a complex format like an information table, they seek additional information. Therefore, we propose that when consumers can seek additional information about a HP, they will perceive its uncertainty as lower compared to when they are not allowed to access it. More formally,

Hypothesis 1. (H1). The perceived uncertainty of product benefits will be reduced after consumers obtain additional information about products from a dissimilar category.

\subsection{Consumption Goals}

When multiple products belong to a single established category, their features and benefits are instantly identified because consumers encode them by reflecting the category in their memory [54]. However, this is not the case when relationships between multiple products are challenging to identify. To establish a connection between seemingly unrelated products, the process involves a category derived by its associated goal [48]. The lack of common category representation may force consumers to form ad hoc categories centered on a goal [54]. Such a category creates a new reference point to build associations between products. Ratneshwar et al. [55] also noted that consumers construct special relationships between dissimilar products only after it makes sense because of a salient goal or usage situation. For example, customers planning a winter holiday would consider "things to bring to holidays". If this is the first time that customers are accomplishing this goal and thus the category is not constructed in memory, consumers may instantly form an ad hoc category containing products such as a book, emergency medicine, blanket, and sweets. Although these products have different concepts individually, they interrelate meaningfully in the newly formed category. Therefore, an ad hoc category can be an effective tool to achieve a goal. 
An ad hoc category decreases uncertainty because it generates a shared value. Even though the product category is not established in consumers' memories, the product's benefits begin to make sense. To better understand the goal-driven category, the role of goals in consumer behavior needs to be explained. Consumers pursue goal achievement by consuming goal-relevant goods or products [56]. Consumers associate their knowledge structure with their motivations to achieve a goal when they find the relevance between their goal and products based on a means-ends relationship [57]. Taylor et al. [58] further addressed how goal activation led to evaluating a product in a more personal context (e.g., usage simulation), thereby stimulating product preference and choice. During this process, consumers go through usage simulation to understand what can be achieved by this product combination [18]. Thereby, goal-derived inference bridges seemingly unrelated products into a meaningful category, which eventually resolves uncertainty.

Moreover, consumers' attempts to look for a product with certain benefits increase the importance of product attributes providing those benefits [59]. Ferguson and Bargh [60] found in their experiment that participants who were highly motivated to win a word game unconsciously evaluated the words "achieve" and "win" more favorably than the ones who did not have similar motivation. Previous studies also showed that when a goal was activated, the stimuli which facilitated it were rated favorably. In the same vein, as consumers' expectations of a product are closely related to their goal, their likelihood of purchasing it increases [61]. Goal-driven behavior is also highlighted in the online commerce context. When a goal is activated, consumers focus on finalizing the purchase process rather than roaming websites [9]. Thus, easy information access and a simple UI are critical for a positive shopping experience.

A consumer goal is a key driver of understanding product benefits, especially when the product category is difficult to retrieve from the consumer's memory. This is important because the memory structure that activates a category cue houses information [54]. If the category is not available to recall from the memory structure, additional information is required, as we proposed in Hypothesis 1 . However, lack of product information may not be involved in evaluating a goal-based category, as an internal cue to understand different concepts is constructed by a goal. More formally,

Hypothesis 2. (H2). Consumers will be more likely to have an improved product attitude toward products from a dissimilar category after seeking product information than before.

Hypothesis 2a. (H2a). When consumers activate their goals, the positive impact of product information on the evaluation of products in a dissimilar category will be mitigated.

\section{Studies}

\subsection{Study Overview}

In the two studies below, we tested the hypotheses outlined above. In the first study, we tested the grounding effect of information seeking, or whether consumers cognitively perceived that additional information found on the mobile commerce page was sufficient to resolve product uncertainty. Study 2 further validated the effect of information seeking on product attitudes and the role of consumption goals. We tested whether priming consumers with consumption goals mitigated the effect of information seeking on product attitude. In both tests, we conducted survey in a mobile commerce format by highlighting a mobile shopping situation. Accordingly, these two studies were not only developed in a mobile context but also accessed by participants from their mobile phones.

We recruited participants through Market Link, an established professional survey company based in South Korea. This company has 6,500,000 Korean panels and partners with Cint, an international survey company that has 22 million US panels. After discussions with Samsung Electronics, we collaboratively decided to recruit Korean participants for Study 1 and US participants for Study 2 to gain insights into the two potential target markets. Although we sacrificed geographic commonality between the two participant groups, we expected they would behave similarly to a prior study showing that there 
was no difference between US and China in terms of perceived usefulness, ease of use, and innovativeness regarding mobile pages [62]. Further, we paid extra attention to the screening procedure to secure representative participants and collect qualified responses. For Study 1, we recruited Korean participants who had a child younger than 3 years old from 8th to 12th June 2020. Among 1034 Korean participants, 905 participants either failed to answer screening questions properly or left mobile pages incomplete, leaving 129 participants. For Study 2, we recruited US participants who had a child between 3 and 6 years old from 20th to 22nd June 2020. Among 159 participants, 59 participants failed to be qualified either by poorly answering screening questions or leaving mobile pages incomplete, leaving 100 participants. Note that the screening rate for each study differed because we distributed our invitation letters massively in Study 1, whereas we invited qualified participants only in Study 2.

For experimental stimuli, we created two hypothetical product bundles designed for families with children. We selected three separate products from dissimilar categories to create each product bundle, which were later showcased under the theme of "child-care products." Since the two newly developed product bundles were hypothetical, participants would find it difficult to imagine usage situations. Hence, our experimental stimuli contained benefit uncertainty.

Next, we assigned each participant group to each experimental stimulus: Korean participants for the sleep monitoring product bundle (Study 1) and US participants for the air monitoring product bundle (Study 2). This decision was made collaboratively. The brand name, Samsung Electronics, was revealed in both studies to minimize any perceived product quality gap among participants.

\subsection{Study 1}

\subsubsection{Experimental Design}

The purpose of Study 1 was to provide evidence that information seeking could reduce the extreme uncertainty about new products from dissimilar categories. Specifically, we proposed that participants would be more likely to reduce their uncertainty about a product after information-seeking behavior than before it. We predicted that the manner of exposing product images and product information on a mobile interface could make a difference in the perceived amount of product information acquired. The study employed a 2 (information seeking: before vs. after) within-subject design. We tested the informationseeking effect in the same group, measuring perceived uncertainty both before and after information-seeking behavior.

\subsubsection{Methodology}

Participants: We recruited 129 participants from South Korea (56.6\% female, $\mathrm{M}_{\mathrm{age}}=37.68$, $\mathrm{SD}=4.34$ ) on Market Link to complete an online study in exchange for monetary compensation. We used the product package, including a combined camera, smart speaker, and monitoring video as stimuli. Each product was sold in a separate product category on the website, and it was the first attempt to assemble these three products as a package. The package itself did not explain much about the features or usage goals due to the strong identity associated with each product. Therefore, additional information may be required to promote package use, especially for the target parent group that needs advice on helping their children sleep. According to the American Academy of Pediatrics (AAP), a quarter of children under the age of $5 \mathrm{do}$ not get adequate sleep. We selected participants who may have been more relevant to the stimuli, parents with children under the age of $3(0-3$; See Table 1$)$. 
Table 1. Study 1 sample distribution.

\begin{tabular}{ccc}
\hline & & $\mathbf{N}$ \\
\hline \multirow{2}{*}{ Sex } & Male & 56 \\
& Female & 73 \\
\hline Total & & 129 \\
\hline \multirow{2}{*}{ Age } & $20-29$ & 2 \\
& $30 \sim 39$ & 80 \\
Total & $40 \sim 49$ & 47 \\
\hline Age of Children & & 129 \\
\hline Total & Under 3 & 129 \\
\hline \multirow{2}{*}{ Income } & & 129 \\
\hline Total & Dual Income & 61 \\
\hline
\end{tabular}

Procedure: Participants started the test by reading a shopping scenario that they were purchasing products for their baby, who had not gotten sufficient sleep lately. Participants were then asked to imagine that they found a Samsung Electronics' sleep monitoring product package on the company's official mobile commerce site. To evaluate the effect of information seeking under uncertainty, we prepared in total three separate mobile pages. The first page (a) included only basic information about HP including its brand name, its name with a short description and a catchphrase. The second page (b) included an image of a single key product of the HP with a verbal description of its benefits. The third page (c) included an image of the full three products (see Figure 1). In the "before information seeking" condition, participants were provided with mobile page (a) only. In the "after information seeking" condition, participants were provided with two mobile pages, (b) and (c). Note that when designing mobile pages, we divided product information into three pages because the amount of information consumers were able to cognitively process was limited due to the small screen size [63]. Because it was important in the "after information seeking condition" that people process information comprehensively and not ignore it, we provided two separately prepared mobile pages, (b) and (c), sequentially.

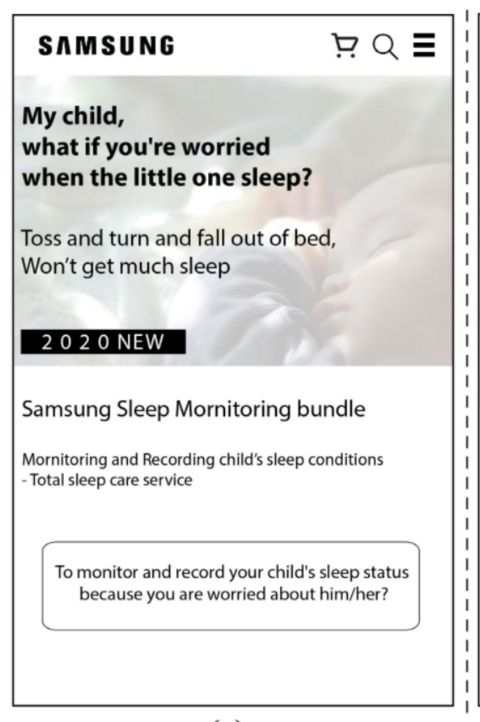

(a)

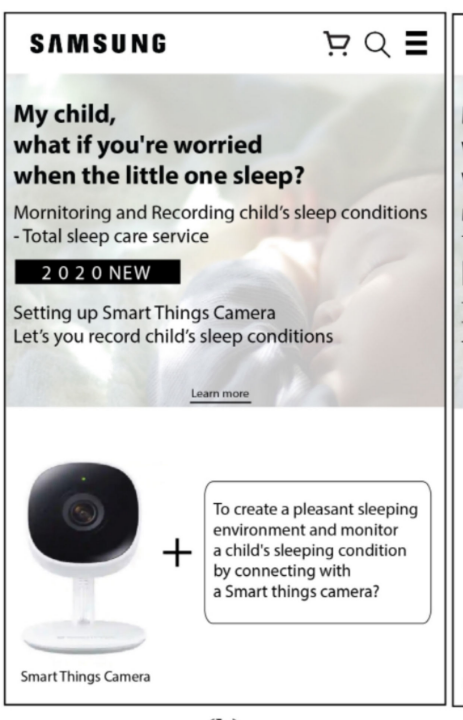

(b)

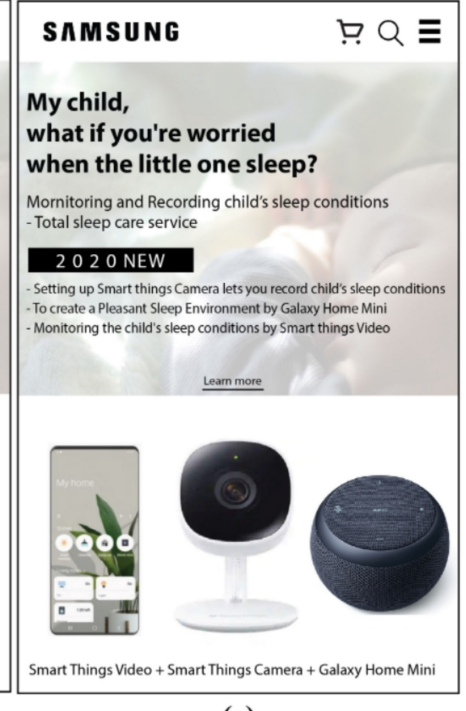

(c)

Figure 1. Study 1 stimuli (a) before information seeking; (b,c) after information seeking. 
Measurement: We measured perceived product uncertainty at two different times, once after page (a) and the other after page (c). First, we measured perceived product uncertainty after participants read the basic information about HP (a). Next, they pressed the "next" button to proceed to page (b) and pressed the "next" button again to reach page (c) so that they were richly and fully informed about the benefits of the HP and how the HP looked. After giving participants one minute to read the information, we measured perceived product uncertainty again. According to Kuhlthau [64], uncertainty diminishes when confidence increases. We measured perceived product uncertainty by referring to the measurement used in his work. We asked participants to indicate how much they felt confident in their understanding of the products $(1=$ very little to $5=$ very much). After finishing the virtual shopping, participants were thanked and logged out from the page.

\subsubsection{Results and Discussion}

We conducted a paired t-test to test H1. Results showed that participants' confidence in understanding the product's use increased after they possessed additional information ( after $\mathrm{b}$ and c) than before ( after $\mathrm{a}, \mathrm{M}_{\text {before }}=2.92 \mathrm{vs} . \mathrm{M}_{\mathrm{after}}=3.64, \mathrm{t}(128)=-5.93, p<0.001$ ), which implied that perceived product uncertainty had decreased. The result illustrated that additional information pages helped participants better understand the use of product packages. Although adding pages requires users' extra time and effort while interacting with the mobile interface, it can positively reduce the perceived uncertainty associated with new products (see Figure 2).

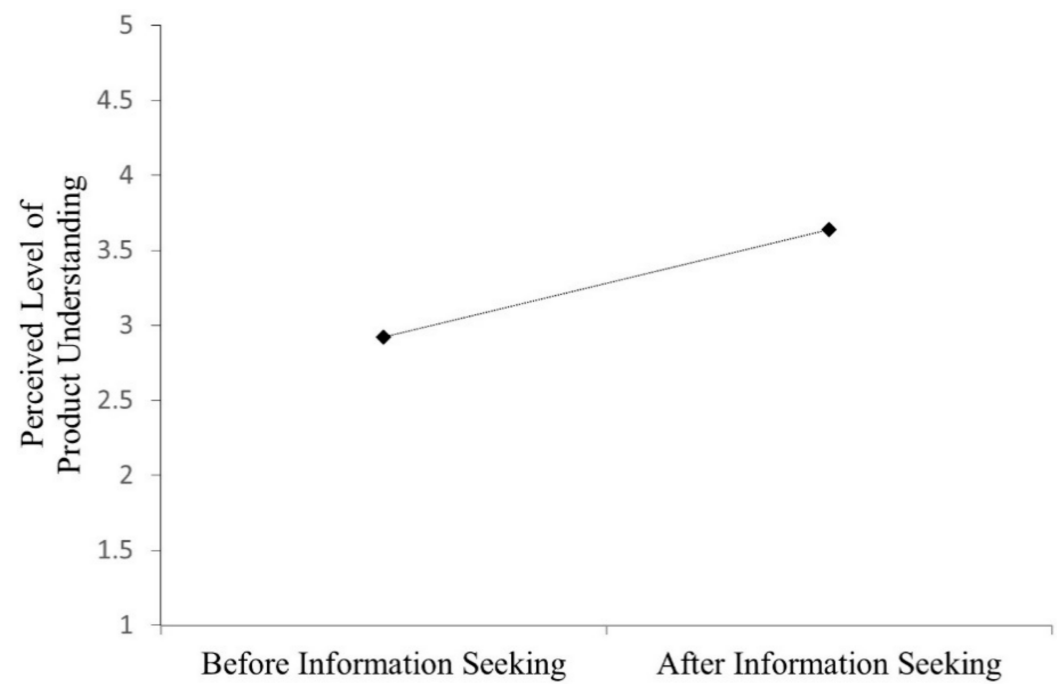

Figure 2. Perceived level of product understanding.

In Study 1, we found that providing product information pages altered participants uncertainty about new products. Specifically, when participants faced a product package constructed of seemingly unrelated products, their perceived uncertainty decreased. Their understanding of the products increased after seeking an additional information page that was provided. Instead of merely reducing information loads to retain a simple mobile interface, planning and designing information access is important in a mobile environment, especially when the products carry high uncertainty. Providing sufficient information diminishes product uncertainty and may affect consumer decision-making. Even though adding more clicks and pages may seem like a bad interface design in terms of usability, it eventually influences consumers' purchase decisions positively as it provides an increased understanding of product benefits. 


\subsection{Study 2}

\subsubsection{Experimental Design}

The goal of Study 2 was twofold. First, we aimed to examine the main effects of information seeking. We suggested that information seeking would be positively correlated with product attitudes. We then tested our prediction that when participants had a goal, their product attitudes remained high regardless of information seeking. On the other hand, participants without a goal would have a lower product attitude before informationseeking behavior and an improved product attitude after doing so. We tested these predictions by having participants evaluate products in two different time sequences: one before information seeking and one after seeking additional product information. We experimentally manipulated a goal situation and a without-goal situation in two separate groups. Thus, the study employed a 2 (information seeking: before vs. after) by 2 (goal: with goal vs. without goal) mixed design wherein the first factor was within participants and the second factor was between participants.

\subsubsection{Methodology}

Participants: We recruited 100 participants from the US ( $78 \%$ female, $\mathrm{M}_{\mathrm{age}}=34.96$, SD $=5.69$ ) on Market Link to complete an online study in exchange for monetary compensation. We recruited parents with a child under age 6, as the product stimuli used in Study 2 were bundled to target these groups. The stimulus used in Study 2 was an air monitoring product bundle consisting of an air conditioner, an air purifier, and an air quality sensor. Although these products were already on the market separately, they had not been presented together as a bundle before. Seemingly non-relevant to each other, the three products operated interactively with a sensor and an IoT function to manage air quality. We selected three products as stimuli because while the function of all these products was well known, additional information-seeking behavior was required to understand the meaning of bridging three products (see Table 2).

Table 2. Study 2 sample distribution.

\begin{tabular}{ccccc}
\hline & & Without Goal & With Goal & Total \\
\hline \multirow{2}{*}{ Sex } & Male & 10 & 12 & 22 \\
& Female & 40 & 38 & 78 \\
\hline Total & & & & 100 \\
\hline \multirow{2}{*}{ Age } & $20 \sim 29$ & 7 & 9 & 16 \\
& $30 \sim 39$ & 37 & 30 & 67 \\
& $40 \sim 49$ & 5 & 11 & 16 \\
\hline Total & $50 \sim 59$ & 1 & 0 & 100 \\
\hline \multirow{2}{*}{ Age of Children } & & & 50 & 100 \\
\hline Total & $3-6$ & 50 & 31 & 100 \\
\hline \multirow{2}{*}{ Income } & Dual Income & 22 & 19 & 53 \\
\hline Total & Single Income & 28 & & 47 \\
\hline
\end{tabular}

Design: Participants were randomly assigned to a between-participant with or without goal condition. In a with-goal situation, we primed participants with a goal on the main page. According to Bargh's $[65,66]$ research, goals can be activated unconsciously through environmental stimuli such as advertisements and product packages. To manipulate the goal, we displayed a main product description page with a parenthood goal such as "Choose only a fresh environment for my child". We manipulated the main page with a neutral paragraph for the without-goal group such as "Control air quality by adopting a modular air purifier" (see Figure 3 for details of stimuli). 


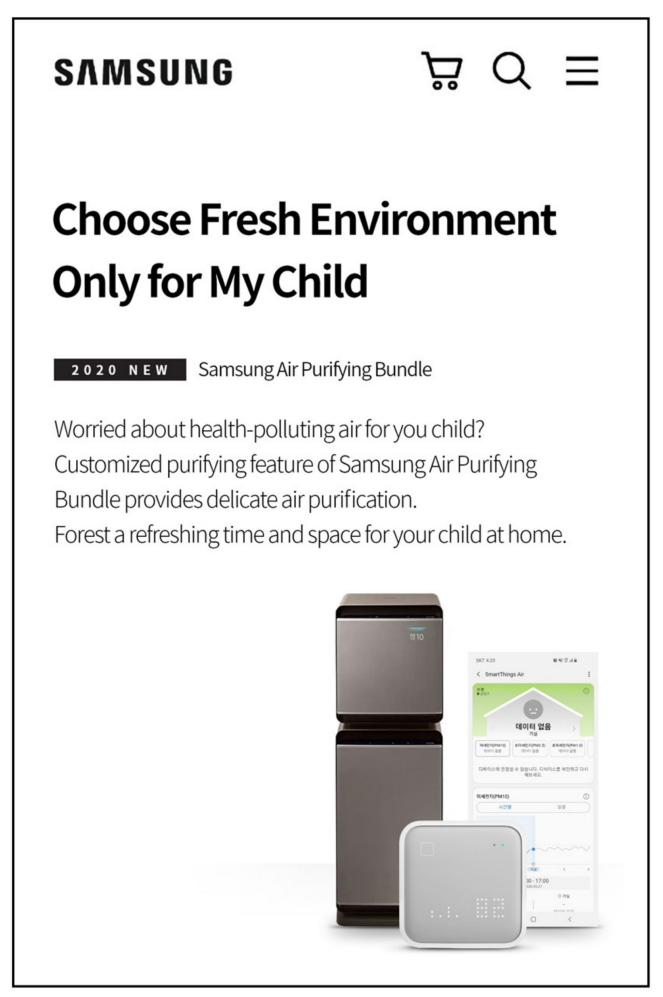

(a)

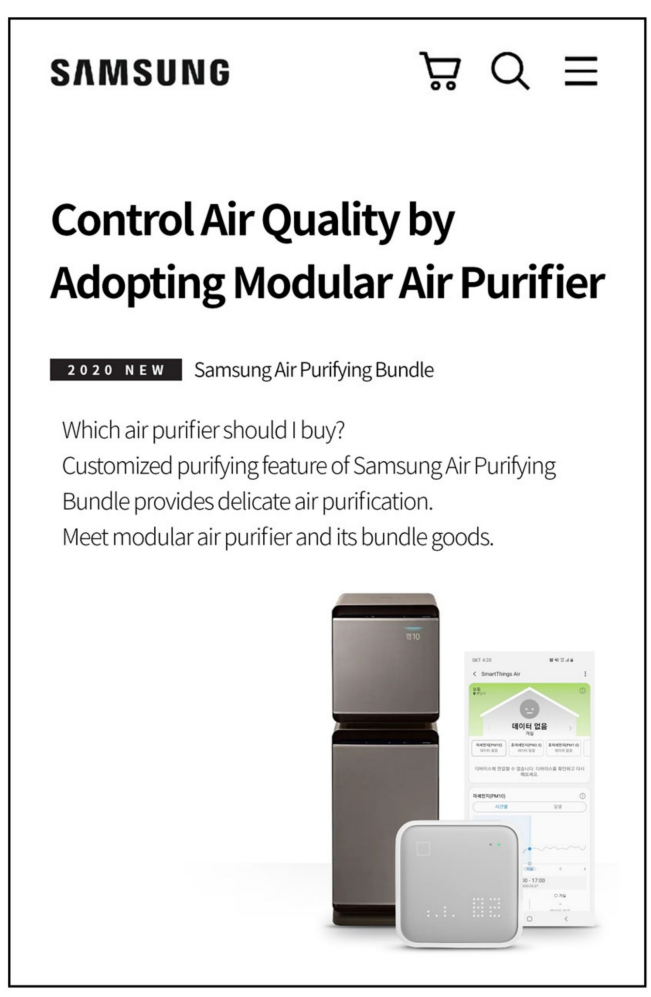

(b)

Figure 3. Study 2 stimuli (a) with-goal condition; (b) without-goal condition.

Procedure: After carefully reading the first product description page, participants continued to see more product description details. We measured product attitude in two different time sequences. Note that product attitude toward a particular brand is regarded as a direct determinant of purchase intention because it is modeled as a function of specific beliefs and other reactions to product attributes or purchase consequences [67]. Product attitude was first measured before participants searched for additional product information and secondly was measured after they clicked and viewed additional product information. We measured product attitudes by asking participants how attractive the product package was $(1=$ unattractive to $5=$ very attractive $)$ and how favorably they felt about the product package $(1=$ unfavorable to $5=$ very favorable). Two items measuring product attitude were summed for this purpose (Cronbach's $\alpha=0.81$ ). After finishing the virtual shopping, participants were thanked and logged out from the page.

\subsubsection{Results and Discussion}

The measure of perceived goal satisfaction was analyzed to check the main product description page's adequacy for the study. As expected, a one-way ANOVA performed on the manipulation check item revealed a statistically significant difference between the two groups $(\mathrm{F}(1,99)=14.21, p=0.000)$. This result indicated that the group who read a goal-oriented product description perceived that the product package met their parenthood goal $(\mathrm{M}=4.04, \mathrm{SD}=0.83)$ at a higher rate than the without-goal group $(\mathrm{M}=3.30, \mathrm{SD}=$ 1.11), who read a product description that did not have a goal-related description. This suggested that the manipulation was successful.

Before our main analysis, a paired $t$-test showed a significant main effect $(p<0.01)$ that when participants proceeded to the additional page to view more specific product information, they showed a higher product attitude $(\mathrm{M}=4.14)$ than when participants did not access additional product information $(M=4.01)$. Supporting Hypothesis $2 \mathrm{a}$, this result indicated that information-seeking behavior increased participants' attitudes toward the product. To provide interaction effect support for Hypotheses $2 \mathrm{a}$, we conducted a repeated measure ANOVA on product attitude before and after seeking additional 
product information on the goal-primed group and the control group. As expected, the interaction effect was significant $(\mathrm{F}(1,98)=3.93, p \leq 0.05)$. Consistent with our Hypothesis $2 \mathrm{a}$, participants who did not have an activated goal showed a more favorable product attitude toward the product after they undertook information-seeking behavior $\left(\mathrm{M}_{\text {before }}\right.$ $=3.93$ vs. $\mathrm{M}_{\text {after }}=4.20$ ). In contrast, accessing an additional information page did not influence product attitude among participants who had an activated goal $\left(\mathrm{M}_{\text {before }}=4.20\right.$ vs. after $=4.19$; see Figure 4$)$. Note that we did not find any gender difference in terms of product attitude $\left(\mathrm{M}_{\text {male }}=4.15\right.$ vs. $\left.\mathrm{M}_{\text {female }}=4.26 ; \mathrm{F}(1,98)=0.16, p>0.05\right)$. Differently from the intuitive prediction that women may be more influenced by a parenthood goal message type as they usually buy the products related to children, our data showed that male participants were influenced by goal message type as much as female participants. We believe our findings echo the findings that male consumers do not behave differently from female consumers in the online shopping context [68].

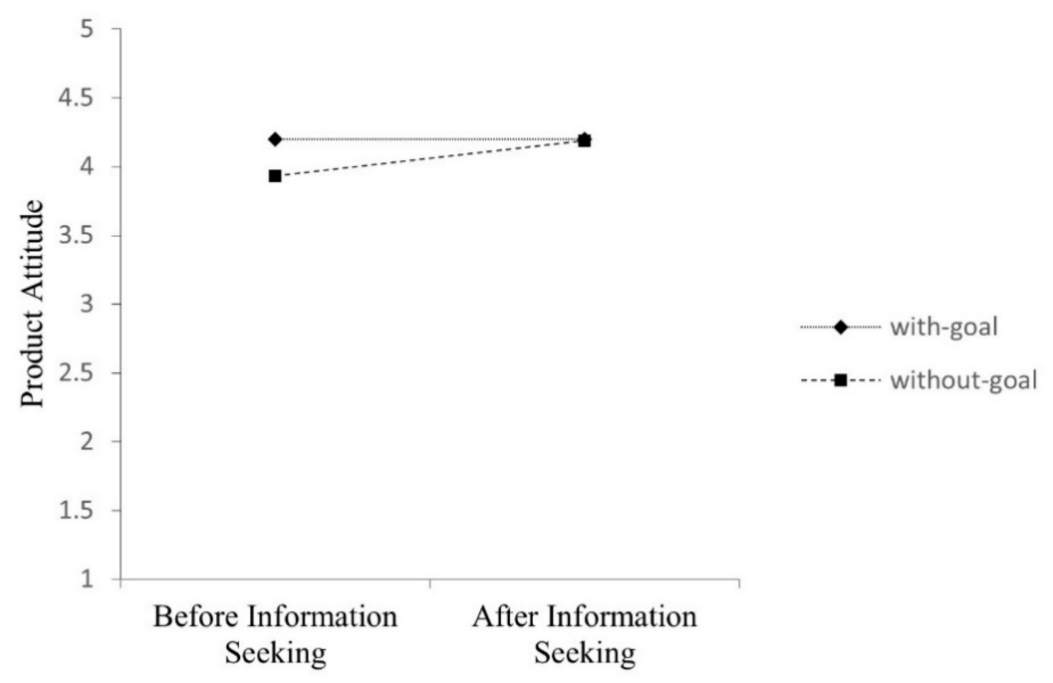

Figure 4. Purchase attitude as a function of information seeking and consumption goal.

Study 2 demonstrated that when shopping for hybrid products in mobile commerce, information-seeking behavior affected product evaluation. Participants evaluated products more positively after they clicked to view additional information than before they sought additional information. Moreover, we found the moderating role of an activated goal. When participants had an activated goal, they had a more-positive product attitude than participants who did not have an activated goal before information-seeking behavior. However, their product attitudes did not increase significantly after the product information, remaining at the same positive level of product attitude. In contrast to the goal condition, participants in the without-activated-goal condition improved their product attitudes after information seeking. Although information seeking in shopping hybrid products is essential to increase product attitudes, goal activation can reduce its influence.

\section{Conclusions}

\subsection{Summary of Findings}

Recent research shows the positive effects of designing a fast and straightforward user interface for an e-commerce website. Minimizing the number of pages and information load to speed up navigation have been chosen as design practices by UI designers. Especially in a mobile context, good usability is underscored even more as essential to providing a pleasant user experience. In this research, we investigated whether increasing the number of information pages influenced product evaluation. More specifically, we tested whether exposure to additional product information in mobile commerce increased or decreased product evaluation. We further explored the moderating effects of consumption goals on product evaluation when consumers faced unusual product bundles in mobile 
commerce. We showed that reaching additional information pages when consumers evaluated product bundles that combined seemingly unrelated products had positive implications for product evaluation. The information-seeking effect was weakened when consumers had a consumption goal.

Study 1 showed that consumers who clicked a button to navigate to a page with additional product information had more confidence in their understanding of a product than before they proceeded to the additional page. This result demonstrated the positive effect of information-seeking behavior on evaluating new product bundles, especially in lowering benefit uncertainty. Providing product information increased satisfaction with perceived product understanding even if the total number of pages increased, and it required pressing a button to reach the information page. Study 2 examined whether the effect of information seeking also influenced product evaluation. Consumers who perceived that they had more information evaluated the new product bundles more positively. This effect was moderated by consumption goals. Consumers who had a consumption goal evaluated new product bundles positively regardless of a modest information load and were not affected by additional information-seeking behavior.

We want to emphasize that our experiments were carefully designed and our participants were carefully recruited, suggesting that our findings have strong external validity. Our sample represented the target users of the new HPs in both studies, who are parents with children aged 0-3 for the bundle used in Study 1 and aged 4-6 for the bundle used in Study 2. Because product bundles presented in both Study 1 and Study 2 were a combination of home electronics products specialized for the care of children and each sample population was subdivided by their child's age, our sample distribution had the advantage of increased personal relevance. This provides evidence for manufacturers' future sales planning. This also applies to our survey method. We conducted both experiments on mobile devices to control the information load per page and swiping motion. Considering that consumer behavior differs according to whether it is on the web or mobile, UI design for mobile commerce similarly differs. Restricting survey access to mobile-only, therefore, matches the goal of measuring consumer behavior in mobile commerce.

\subsection{Academic Contributions}

The current work both provides an academic contribution and has empirical implications. The result contributes to the scholarly literature on new product adoption topics, information-seeking behavior, and the role of goals. First, even though the number of new products in the market is increasing, relatively few articles have documented the factors influencing new product adoption. Especially, no research has yet bridged new product adoption with information seeking and consumption goals. We suggest that information seeking and consumption goals together affect new product adoption.

Moreover, our results call for further examination of UX design research from a sales perspective. We showed that what has been thought to harm usability (e.g., increasing pages) increased product attitude when it came to evaluating new products. As existing research examining UX design in mobile commerce has limited its scope to usability, future UX research should expand its range to analyzing consumer decision-making such as purchase intention, willingness to pay, or product evaluation.

\subsection{Managerial Implications}

Two critical empirical implications can be drawn from our research. First, it provides fresh insights into marketers who aim to sell various types of new products including HPs in mobile commerce. We show that providing more information about products increases new product evaluation, hence lowering the new product adoption bar. Second, it has demonstrated the importance of consumption goals. Aligned with the first empirical implication, the consumption goal minimizes the difficulty of consumer persuasion in new product adoption. The goal plays a role in increasing product attitude, even if there is minimal information provided. 


\section{Limitations and Future Research}

While we provide important insights for mobile commerce research, there are six limitations that we must acknowledge. First, our research is heavily based on a foundation of research on a general web environment. The activating goal in the web environment should navigate consumer behavior, including information-seeking behavior, as consumers with activated goals engage with favorable cognitive attitudes [69]. However, our experiments were conducted under mobile conditions. Hence, we do not explain whether this cognitive influence occurs only in a mobile context or can be applied to other online commerce platforms. A research opportunity exists in mobile commerce, as two contradicting perspectives are available. On one hand, context matters. We do not expect that our findings hold in any non-mobile context because we tested consumers' mobile behavior by conducting experiments employing a hypothetical mobile environment. Non-mobile contexts include brick-and-mortar stores, online websites, and any other alternative environments in which non-visual information can be processed. Indeed, there is evidence that people experience fatigue when they are overwhelmed by information on mobile pages but not on websites [70]. On the other hand, the consumption goal is context-free. It is one of the fundamental psychological concepts and may influence consumer behavior regardless of context. For example, when a consumer aims to take care of her baby, her attitude toward a baby-care HP is likely to be higher than when she does not, regardless of whether her goal is activated by sales representatives, online websites, or radio commercials. This suggests that a consumption goal is a context-free, psychological variable which determines a consumer's attitude. Unfortunately, we did not test whether context (mobile vs. non-mobile) moderated the impact of consumption goals in our manuscript. According to recent research about the "direct-touch" effect, people are more likely to choose an affect-laden alternative over a cognitively superior one when they use a touch interface (e.g., the iPad) compared to a non-touch interface (e.g., a desktop computer with a mouse). In the future, multiple mobile-context mediators should be rigorously measured to better understand the mechanisms involved in how information-seeking behavior influences consumers' evaluations of HPs.

Second, we did not firmly establish whether lowering uncertainty was why information seeking led to more positive product evaluation in the mobile context. New product adoption is associated with uncertainty because some unfamiliar product elements carry the risk of having lower quality than expected [71]. Our experiments are based on existing theories about the uncertainty associated with new products. However, we do not have an explanation regarding whether positive product evaluation occurs because information seeking lowers uncertainty. It remains unclear whether the effect would differ when consumers evaluated existing products. Future research requires further investigation of whether information seeking's effect is restricted to products with uncertainty and does not occur when consumers evaluate familiar or existing products.

Third, although we focused on UX design in mobile commerce, enhancing product evaluation in mobile commerce can be approached by the theory of processing fluency. Prior research suggests that people's attitudes toward a target become more favorable when they experience its fluent processing [72]. Processing fluency has been shown to positively affect product evaluation [73] and brand choice [74]. Moreover, according to the goal fluency suggested by Labroo and Lee [72], adding a focal goal dissimilar to product attributes decreases processing fluency, consequently lowering product evaluation. The possibility of conflicting assumptions to explain the result implies that the effect depends on the context, and further exploration can be conducted in the future.

Fourth, the commercial impact of UI needs to be further studied beyond attitude. We certainly believe that whether consumers add an HP to their shopping carts or even make a purchase needs to be investigated in the future. However, this question is out of scope for our current research because we are specifically interested in consumers' perceived uncertainty and their attitude toward HPs. Note that ample research suggests that a good 
attitude does not necessarily result in a good outcome [75]. Put simply, our dependent variables are psychological ones rather than behavioral ones.

Fifth, critically important practical variables should be further considered. One example is consumers' control of conditions. In our experiments, we tested relationships not when participants had freedom to choose one out of two conditions but when they were assigned to one. Note that control is a powerful trigger that affects people's behavior. There is empirical evidence showing that the presence of control has a significant effect on the regulation of emotion, cognition, and physiology [76]. Indeed, simply expressing preferences through choices can reinforce the perception of individual control when deemed optimal for the desired outcome. When controlling the environment by choosing the behaviors that achieve desirable outcomes and avoid undesirable outcomes, consumers may be less influenced by information seeking or consumption goals.

Lastly, this topic can be further explored in the social commerce context. Social commerce has become a popular research topic due to its fast-growing market size [77]. In social commerce, information created and shared by consumers significantly influences product attitudes and purchase intentions [78,79]. Not only consumer-generated information, but also visual communications observed on social media invite further investigation for the dynamics of information type and user interaction [80]. While we examined the effects of providing information per se, future researchers will discover profound implications by comparing the effects of different types of information including consumer generated information, official video advertisements, and information charts.

Author Contributions: Conceptualization, S.H. (Sooa Hwang) and J.J.; methodology, S.H. (Sooa Hwang) and H.P.; validation, S.H. (Sooa Hwang), H.P., and J.J.; writing—original draft preparation, S.H. (Sooa Hwang), H.P., K. O., S.H. (Sangwoong Hwang), J.J.; writing-review and editing, S.H. (Sooa Hwang) and J.J.; visualization, S.H. (Sooa Hwang) and H.P.; supervision, J.J.; All authors have read and agreed to the published version of the manuscript.

Funding: This research received no external funding.

Institutional Review Board Statement: Ethical review and approval were waived for this study, because data collection was conducted by a professional market research company which has its own pool of panels who agreed on the purpose of the study and voluntarily participated in the study as anonymous.

Informed Consent Statement: Informed consent statement was obtained from the participants involved in the study.

Data Availability Statement: The data collected and presented in this study are available on request from the corresponding author.

Acknowledgments: The authors would like to express sincere gratitude to Seokmin Oh, Vice President of the Corporate Design Center, Samsung Electronics, for generously granting access to documents and data regarding the development of its childcare products. We also gratefully acknowledge the Corporate Design Center's fundamental support in providing us with extra information about the project.

We further appreciate an anonymous reviewer who proposed a valuable hypothesis regarding gender difference in terms of product attitude and provided insights for future research topics.

Conflicts of Interest: The authors declare no conflict of interest.

\section{References}

1. Chong, A.Y.-L. Mobile Commerce Usage Activities: The Roles of Demographic and Motivation Variables. Technol. Forecast. Soc. Chang. 2013, 80, 1350-1359. [CrossRef]

2. 2018 Global M-Commerce Report. Available online: www.researchandmarkets.com (accessed on 2 December 2020).

3. Ngai, E.W.T.; Gunasekaran, A. A Review for Mobile Commerce Research and Applications. Decis. Support Syst. $2007,43,3-15$. [CrossRef]

4. Ahmad, Z.; Ibrahim, R. Mobile Commerce (M-Commerce) Interface Design: A Review of Literature. OSR J. Comput. Eng. 2017, 19, 66-70. [CrossRef] 
5. Wu, Y.-L.; Ye, Y.-S. Understanding Impulsive Buying Behavior in Mobile Commerce. In PACIS; 2013; p. 142. Available online: http:/ / aisel.aisnet.org/pacis2013/142 (accessed on 18 December 2020).

6. Lee, Y.E.; Benbasat, I. Interface Design for Mobile Commerce. Commun. ACM 2003, 46, 48-52. [CrossRef]

7. Buyukkokten, O.; Kaljuvee, O.; Garcia-Molina, H.; Paepcke, A.; Winograd, T. Efficient Web Browsing on Handheld Devices Using Page and Form Summarization. ACM Trans. Inf. Syst. 2002, 20, 82-115. [CrossRef]

8. Kim, H.; Kim, J.; Lee, Y. An Empirical Study of Use Contexts in the Mobile Internet, Focusing on the Usability of Information Architecture. Inf. Syst. Front. 2005, 7, 175-186. [CrossRef]

9. Jung, W. The Effect of Representational UI Design Quality of Mobile Shopping Applications on Users' Intention to Shop. Procedia Comput. Sci. 2017, 121, 166-169. [CrossRef]

10. Wolfinbarger, M.; Gilly, M.C. Shopping Online for Freedom, Control, and Fun. Calif. Manag. Rev. 2001, 43, 34-55. [CrossRef]

11. Porter, J. Testing the Three-Click Rule. User Interface Eng. 2003. Available online: www.uie.com/articles/three_click_rule (accessed on 27 December 2020).

12. Krug, S. The Do-It-Yourself Guide to Finding and Fixing Usability Problems; New Riders: Indianapolis, IN, USA, 2009; pp. 102-128. ISBN 978-0321657299.

13. Agarwal, A.; Meyer, A. Beyond Usability: Evaluating Emotional Response as an Integral Part of the User Experience. In CHI'09 Extended Abstracts on Human Factors in Computing Systems; Association for Computing Machinery: Boston, MA, USA, 2009; pp. 2919-2930. [CrossRef]

14. Chen, J.; Teng, L.; Yu, Y.; Yu, X. The Effect of Online Information Sources on Purchase Intentions between Consumers with High and Low Susceptibility to Informational Influence. J. Bus. Res. 2016, 69, 467-475. [CrossRef]

15. Chiu, C.; Wang, E.T.G.; Fang, Y.; Huang, H. Understanding Customers' Repeat Purchase Intentions in B2C E-commerce: The Roles of Utilitarian Value, Hedonic Value and Perceived Risk. Inf. Syst. J. 2014, 24, 85-114. [CrossRef]

16. Kim, M.; Lennon, S.J. Television Shopping for Apparel in the United States: Effects of Perceived Amount of Information on Perceived Risks and Purchase Intentions. Fam. Consum. Sci. Res. J. 2000, 28, 301-331. [CrossRef]

17. Novak, T.P.; Hoffman, D.L.; Duhachek, A. The Influence of Goal-directed and Experiential Activities on Online Flow Experiences. J. Consum. Psychol. 2003, 13, 3-16. [CrossRef]

18. Gibbert, M.; Mazursky, D. How Successful Would a Phone-Pillow Be: Using Dual Process Theory to Predict the Success of Hybrids Involving Dissimilar Products. J. Consum. Psychol. 2009, 19, 652-660. [CrossRef]

19. Alexander, N. Defining Brand Values through Sponsorship. Int. J. Retail Distrib. Manag. 2009, 37, 346-357. [CrossRef]

20. Nguyen, T.; Joo, J. Digital Strikes Back: Reading Digital Clocks Decreases New Product Adoption. Arch. Des. Res. 2019, 32, 103-114. [CrossRef]

21. Zhao, M.; Hoeffler, S.; Dahl, D.W. Imagination Difficulty and New Product Evaluation. J. Prod. Innov. Manag. 2012, 29, 76-90. [CrossRef]

22. Ma, Z.; Yang, Z.; Mourali, M. Consumer Adoption of New Products: Independent versus Interdependent Self-Perspectives. J. Mark. 2014, 78, 101-117. [CrossRef]

23. Gourville, J.T. Eager Sellers and Stony Buyers: Understanding the Psychology of New-Product Adoption. Harv. Bus. Rev. 2006, 84, 98-106.

24. Hoeffler, S. Measuring Preferences for Really New Products. J. Mark. Res. 2003, 40, 406-420. [CrossRef]

25. Herzenstein, M.; Posavac, S.S.; Brakus, J.J. Adoption of New and Really New Products: The Effects of Self-Regulation Systems and Risk Salience. J. Mark. Res. 2007, 44, 251-260. [CrossRef]

26. Claudy, M.C.; Garcia, R.; O'Driscoll, A. Consumer Resistance to Innovation-A Behavioral Reasoning Perspective. J. Acad. Mark. Sci. 2015, 43, 528-544. [CrossRef]

27. Gill, T.; Dube, L. What Is a Leather Iron or a Bird Phone? Using Conceptual Combinations to Generate and Understand New Product Concepts. J. Consum. Psychol. 2007, 17, 202-217. [CrossRef]

28. Wilkenfeld, M.J.; Ward, T.B. Similarity and Emergence in Conceptual Combination. J. Mem. Lang. 2001, 45, 21-38. [CrossRef]

29. Wisniewski, E.J. Construal and Similarity in Conceptual Combination. J. Mem. Lang. 1996, 35, 434-453. [CrossRef]

30. Moore, W.L.; Lehmann, D.R. Individual Differences in Search Behavior for a Nondurable. J. Consum. Res. 1980, 7, 296-307. [CrossRef]

31. Reilly, M.D.; Conover, J.N. Meta-Analysis: Integrating Results from Consumer Research Studies. ACR N. Am. Adv. 1983, 10, 509-573.

32. James, F.E.; Roger, D.B.; Paul, W.M. Consumer Behavior, 5th ed.; The Dryden Press: New York, NY, USA, $1986 ;$ pp. $23-39$.

33. Hoyer, W.D.; MacInnis, D.J.; Pieters, R. Consumer Behavior; Cengage Learning: Boston, MA, USA, 2013 ; pp. $184-212$.

34. Newman, J.W. Consumer External Search: Amount and Determinants. In Consumer and Industrial Buying Behavior; Elsevier: New York, NY, USA, 1997; pp. 79-94. ISBN 0-444-00230-8.

35. Srinivasan, N. Pre-Purchase External Search for Information. Rev. Mark. 1990, 4, 153-189.

36. Janiszewski, C. The Influence of Display Characteristics on Visual Exploratory Search Behavior. J. Consum. Res. 1998, 25, $290-301$. [CrossRef]

37. Vogt, C.A.; Fesenmaier, D.R. Expanding the Functional Information Search Model. Ann. Tour. Res. 1998, 25, 551-578. [CrossRef]

38. Artandi, S. Information Concepts and Their Utility. J. Am. Soc. Inf. Sci. 1973, 24, 242-245. [CrossRef] 
39. Flanagin, A.J.; Metzger, M.J.; Pure, R.; Markov, A.; Hartsell, E. Mitigating Risk in Ecommerce Transactions: Perceptions of Information Credibility and the Role of User-Generated Ratings in Product Quality and Purchase Intention. Electron. Commer. Res. 2014, 14, 1-23. [CrossRef]

40. Castaño, R.; Sujan, M.; Kacker, M.; Sujan, H. Managing Consumer Uncertainty in the Adoption of New Products: Temporal Distance and Mental Simulation. J. Mark. Res. 2008, 45, 320-336. [CrossRef]

41. Cheung, C.M.K.; Thadani, D.R. The Impact of Electronic Word-of-Mouth Communication: A Literature Analysis and Integrative Model. Decis. Support Syst. 2012, 54, 461-470. [CrossRef]

42. Van der Heijden, H.; Verhagen, T.; Creemers, M. Understanding Online Purchase Intentions: Contributions from Technology and Trust Perspectives. Eur. J. Inf. Syst. 2003, 12, 41-48. [CrossRef]

43. Kuhlthau, C.C. A Principle of Uncertainty for Information Seeking. J. Doc. 1993, 49, 339-355. [CrossRef]

44. Nicholas, D.; Dobrowolski, T.; Withey, R.; Russell, C.; Huntington, P.; Williams, P. Digital Information Consumers, Players and Purchasers: Information Seeking Behaviour in the New Digital Interactive Environment. Aslib Proc. 2003, 55, 22-31. [CrossRef]

45. Moreau, C.P.; Markman, A.B.; Lehmann, D.R. What Is It? Categorization Flexibility and Consumers' Responses to Really New Products. J. Consum. Res. 2001, 27, 489-498. [CrossRef]

46. Jhang, J.H.; Grant, S.J.; Campbell, M.C. Get It? Got It. Good! Enhancing New Product Acceptance by Facilitating Resolution of Extreme Incongruity. J. Mark. Res. 2012, 49, 247-259. [CrossRef]

47. Rogers, E.M. Diffusion of Innovations: Modifications of a Model for Telecommunications; Die Diffusion von Innovationen in der Telekommunikation; Springer: New York, NY, USA, 1995; pp. 25-38. [CrossRef]

48. Barsalou, L.W. Context-Independent and Context-Dependent Information in Concepts. Mem. Cognit. 1982, 10, 82-93. [CrossRef]

49. Camerer, C.; Weber, M. Recent Developments in Modeling Preferences: Uncertainty and Ambiguity. J. Risk Uncertain. 1992, 5, 325-370. [CrossRef]

50. Wells, C.; van Thomme, J.; Maurer, P.; Hanna, A.; Pevehouse, J.; Shah, D.V.; Bucy, E. Coproduction or Cooptation? Real-Time Spin and Social Media Response during the 2012 French and US Presidential Debates. French Polit. 2016, 14, 206-233. [CrossRef]

51. Kim, J.-H.; Kim, M.; Kandampully, J. The Impact of Buying Environment Characteristics of Retail Websites. Serv. Ind. J. 2007, 27, 865-880. [CrossRef]

52. Yoo, J.; Kim, M. The Effects of Online Product Presentation on Consumer Responses: A Mental Imagery Perspective. J. Bus. Res. 2014, 67, 2464-2472. [CrossRef]

53. Mikalef, P.; Sharma, K.; Pappas, I.O.; Giannakos, M.N. Online Reviews or Marketer Information? An Eye-Tracking Study on Social Commerce Consumers. In Conference on E-Business, E-Services and E-Society; Springer: New York, NY, USA, 2017 ; pp. 388-399. [CrossRef]

54. Barsalou, L.W. Ad Hoc Categories. Mem. Cognit. 1983, 11, 211-227. [CrossRef] [PubMed]

55. Ratneshwar, S.; Barsalou, L.W.; Pechmann, C.; Moore, M. Goal-Derived Categories: The Role of Personal and Situational Goals in Category Representations. J. Consum. Psychol. 2001, 10, 147-157. [CrossRef]

56. Bagozzi, R.P.; Dholakia, U. Goal Setting and Goal Striving in Consumer Behavior. J. Mark. 1999, 6, 19-32. [CrossRef]

57. Spreng, R.A.; Olshavsky, R.W. A Desires Congruency Model of Consumer Satisfaction. J. Acad. Mark. Sci. 1993, 21, 169-177. [CrossRef]

58. Taylor, S.E.; Pham, L.B.; Rivkin, I.D.; Armor, D.A. Harnessing the Imagination: Mental Simulation, Self-Regulation, and Coping. Am. Psychol. 1998, 53, 429. [CrossRef]

59. Gutman, J. A Means-End Chain Model Based on Consumer Categorization Processes. J. Mark. 1982, 46, 60-72. [CrossRef]

60. Ferguson, M.J.; Bargh, J.A. Liking Is for Doing: The Effects of Goal Pursuit on Automatic Evaluation. J. Pers. Soc. Psychol. 2004, 87, 557. [CrossRef] [PubMed]

61. Westbrook, R.A.; Reilly, M.D. Value-Percept Disparity: An Alternative to the Disconfirmation of Expectations Theory of Consumer Satisfaction. ACR N. Am. Adv. 1983, 256-261.

62. Dai, H.; Palvi, P.C. Mobile Commerce Adoption in China and the United States: A Cross-Cultural Study. ACM SIGMIS Database Adv. Inf. Syst. 2009, 40, 43-61. [CrossRef]

63. Shankar, V.; Venkatesh, A.; Hofacker, C.; Naik, P. Mobile Marketing in the Retailing Environment: Current Insights and Future Research Avenues. J. Interact. Mark. 2010, 24, 111-120. [CrossRef]

64. Kuhlthau, C.C. The Role of Experience in the Information Search Process of an Early Career Information Worker: Perceptions of Uncertainty, Complexity, Construction, and Sources. J. Am. Soc. Inf. Sci. 1999, 50, 399-412. [CrossRef]

65. Bargh, J.A. Auto-Motives: Preconscious Determinants of Social Interaction. Handb. Motiv. Cogn. Found. Soc. Behav. 1990, 2, 93-130.

66. Bargh, J.A.; Gollwitzer, P.M.; Lee-Chai, A.; Barndollar, K.; Trötschel, R. The Automated Will: Nonconscious Activation and Pursuit of Behavioral Goals. J. Pers. Soc. Psychol. 2001, 81, 1014-1027. [CrossRef]

67. Howard, J.A.; Sheth, J.N. A Theory of Buyer Behavior. Mark. Crit. Perspect. Bus. Manag. 2001, 3, 81-105. [CrossRef]

68. Kim, J.; Forsythe, S. Adoption of Virtual Try-on Technology for Online Apparel Shopping. J. Interact. Mark. 2008, 22, 45-59. [CrossRef]

69. Chang, S.-H.; Chih, W.-H.; Liou, D.-K.; Yang, Y.-T. The Mediation of Cognitive Attitude for Online Shopping. Inf. Technol. People 2016, 29, 618-646. [CrossRef] 
70. Kang, J.W.; Chun, Y.S.; Moon, N.J. A Comparison of Accommodation and Ocular Discomfort Change According to Display Size of Smart Devices. BMC Ophthalmol. 2021, 21, 70. [CrossRef]

71. Kalish, S. A New Product Adoption Model with Price, Advertising, and Uncertainty. Manage. Sci. 1985, 31, 1569-1585. [CrossRef]

72. Labroo, A.A.; Lee, A.Y. Between Two Brands: A Goal Fluency Account of Brand Evaluation. J. Mark. Res. 2006, 43, $374-385$. [CrossRef]

73. Lee, A.Y.; Labroo, A.A. The Effect of Conceptual and Perceptual Fluency on Brand Evaluation. J. Mark. Res. 2004, 41, 151-165. [CrossRef]

74. Lee, A.Y. Effects of Implicit Memory on Memory-Based versus Stimulus-Based Brand Choice. J. Mark. Res. 2002, 39, 440-454. [CrossRef]

75. Spears, N.; Singh, S.N. Measuring Attitude toward the Brand and Purchase Intentions. J. Curr. Issues Res. Advert. 2004, 26, 53-66. [CrossRef]

76. Leotti, L.A.; Iyengar, S.S.; Ochsner, K.N. Born to Choose: The Origins and Value of the Need for Control. Trends Cogn. Sci. 2010, 14, 457-463. [CrossRef]

77. Kim, N.; Kim, W. Do Your Social Media Lead You to Make Social Deal Purchases? Consumer-Generated Social Referrals for Sales via Social Commerce. Int. J. Inf. Manag. 2018, 39, 38-48. [CrossRef]

78. Zhang, P.; Wang, C. The Evolution of Social Commerce: An Examination from the People, Business, Technology, and Information Perspective. Wang Chingning Ping Zhang Evol. Soc. Commer. Exam. People Bus. Technol. Inf. Perspect. Commun. AIS 2012, 31, 105-127. Available online: https:/ / ssrn.com/abstract=2352587 (accessed on 4 May 2021).

79. Cheong, H.J.; Morrison, M.A. Consumers' Reliance on Product Information and Recommendations Found in UGC. J. Interact. Advert. 2008, 8, 38-49. [CrossRef]

80. Mikalef, P.; Sharma, K.; Pappas, I.O.; Giannakos, M. Seeking Information on Social Commerce: An Examination of the Impact of User-and Marketer-Generated Content through an Eye-Tracking Study. Inf. Syst. Front. 2020, 1-14. [CrossRef] 